\title{
Braille learning: One modality is sometimes better than two
}

\author{
SLATER E. NEWMAN and WILSON L. SAWYER \\ North Carolina State University, Raleigh, North Carolina \\ ANTHONY D. HALL \\ IBM Corporation, Research Triangle Park, North Carolina \\ and \\ LAUREL G. J. HILL \\ North Carolina State University, Raleigh, North Carolina
}

\begin{abstract}
On study trials, subjects examined braille symbols (for the letters A-J or K-T) visually, haptically, or under one of two bimodality conditions in which use of one or both modalities was possible. All subjects were tested haptically. Performance was best for the visual group, next best for the two bimodality groups, and poorest for the haptic group. These results are to some extent interpretable using Freides' (1974) modality-adeptness hypothesis.
\end{abstract}

In a number of experiments, learning the names for braille symbols has been facilitated when, on study trials, the symbols are examined visually (as compared with haptically) even though subjects are tested haptically (Hall \& Newman, 1987; Newman et al., 1982). The present experiment was done to determine whether having the symbols available for study in both modalities would affect subsequent performance on a haptic test. Thus, in addition to the visual and haptic study conditions used in previous experiments, there were two bimodality study conditions. In the simultaneous condition, the braille symbols were presented during the study trials for haptic and visual examination at the same time, whereas in the successive condition, the symbols were available for study in each modality, though only through one modality at a time. Half of the subjects in each of these four conditions learned to name the symbols for A-J, and the rest, the symbols for K-T. Previous research has shown that the symbols for $\mathrm{K}-\mathrm{T}$ are harder to discriminate from one another than are the symbols for A-J; learning to name the symbols for $\mathrm{K}-\mathrm{T}$ is also more difficult than it is for A-J (Hall \& Newman, 1987; Newman, Hall, Foster, \& Gupta, 1984).

\section{METHOD}

The task involved learning a list of paired associates. The study-test procedure was used; there were five study trials, each followed by a test. On the study trials, the braille symbols were presented one at a time for visual $(\mathrm{V})$, haptic $(\mathrm{H})$, visual or haptic $(\mathrm{VOH})$, or visual and

We thank John Calloway, Governor Morehead School for the Blind, for thermoform supplies and the use of thermoform equipment, and Donald Mershon for suggestions relating to the design of equipment for this experiment. Requests for reprints should be addressed to Slater E. Newman, Department of Psychology, Box 7801, North Carolina State University, Raleigh, NC 27695-7801. haptic (VAH) examination, and the subject was instructed to learn the name for the symbol. The letter name was presented on a tape recorder as the symbol was introduced. On the test trials, each item was presented for haptic examination and the subject was to call out its name. The subjects were given $10 \mathrm{sec}$ to examine each item on the study trials and also on the test trials. During haptic examination, the subject explored the symbol by rubbing the flat portion of the index finger of the right hand over the symbol. All subjects were told prior to the first study trial that they would be tested haptically.

The subjects were right-handed undergraduate students at North Carolina State University, who were fulfilling part of a course requirement for introductory psychology. The design was a $2 \times 4$ factorial, since there were two sets of items (A-J and K-T) and four study-modality conditions (visual, haptic, visual and haptic, and visual or haptic). Twelve subjects, 8 male and 4 female, were assigned to each of these eight conditions. Two different sets of study and test orders were used, one set for half the males and females in each treatment. All subjects were run individually.

\section{RESULTS AND DISCUSSION}

The number of correct responses during each of the five test trials was the main dependent variable. The means for the eight treatments are presented in Table 1. An analysis of variance applied to these data gave significant $(p<.001)$ effects for study modality $[F(3,88)=7.26]$, symbol set $[F(1,88)=60.43]$, trials $[F(4,352)=94.43]$, and the interaction of symbol set and trials $[F(4,352)=$ 4.85]. Application of Duncan's test showed that the mean for the visual group exceeded the means for the two bimodality groups, and that these bimodality means exceeded the mean for the haptic group but did not differ from one another. The mean for the A-J items was higher than the K-T mean, and this difference increased with training. Two of these findings replicate the results of our previous experiments (Hall \& Newman, 1987; Newman et al., 1982; Newman et al., 1984)-namely, that subjects who studied the symbols visually did better than those who studied the items haptically, even though all were 
Table 1

Mean Correct Responses During Training

\begin{tabular}{lccccccc}
\hline & & \multicolumn{5}{c}{ Trials } & \\
\cline { 3 - 7 } Treatment & Set & 1 & 2 & 3 & 4 & 5 & Total \\
\hline V & A-J & 5.2 & 8.6 & 8.5 & 8.7 & 9.7 & 40.7 \\
VOH & A-J & 5.2 & 7.3 & 7.9 & 8.0 & 8.8 & 37.2 \\
VAH & A-J & 4.8 & 6.0 & 6.8 & 7.4 & 8.5 & 33.5 \\
H & A-J & 3.0 & 5.5 & 6.7 & 6.1 & 6.6 & 27.9 \\
V & K-T & 3.0 & 4.3 & 5.3 & 5.8 & 7.5 & 25.9 \\
VOH & K-T & 3.4 & 4.1 & 4.2 & 5.1 & 6.0 & 22.8 \\
VAH & K-T & 3.3 & 3.8 & 4.3 & 5.2 & 6.4 & 23.0 \\
H & K-T & 1.9 & 3.2 & 3.8 & 4.1 & 5.3 & 18.3 \\
\hline
\end{tabular}

Note-V = visual, $\mathrm{VOH}=$ visual or haptic, $\mathrm{VAH}=$ visual and haptic, $\mathbf{H}=$ haptic.

tested haptically, and that the A-J set was learned faster than the $\mathrm{K}-\mathrm{T}$ set.

For another set of analyses, the ease of learning each item was determined for each of the conditions, by counting the number of times that item was correct during training. Ranks were then assigned to each item in each condition on that basis. Then, for each pair of treatments for each item set, a rank-order correlation was performed. The results are presented in Table 2.

All of the correlations are positive and all but one are significant $(p<.05)$. When the ranks are summed across modality conditions, the symbols $A$ and $B$ turn out to have been the easiest items in the A-J set and $D$ and $H$, the hardest. For the $\mathrm{K}-\mathrm{T}$ set, $\mathrm{L}$ and $\mathrm{K}$ were the easiest, and $\mathrm{N}$ and $\mathrm{T}$, the hardest. The correlational results suggest that both across treatments and across sets of items one or more similar processes are contributing to difficulty in learning the names of the symbols. These results also replicate those we have obtained previously (Hall \& Newman, 1987; Newman et al., 1984; Newman et al., 1982; Newman, Kindsvater, \& Hall, 1985).

Table 2

Rank-Order Correlations for Item Difficulty Between Treatments

\begin{tabular}{lll} 
& \multicolumn{2}{c}{ Item Sets } \\
\cline { 2 - 3 } Treatments & A-J & K-T \\
\hline V-VOH & $.830 \dagger$ & $.909 \dagger$ \\
V-VAH & $.597^{*}$ & $.885 \dagger$ \\
V-H & $.673^{*}$ & $.649^{*}$ \\
VOH-VAH & $.682^{*}$ & $.964 \dagger$ \\
VOH-H & $.879 \dagger$ & $.633^{*}$ \\
VAH-H & $.682^{*}$ & .515 \\
\hline
\end{tabular}

Note $-\mathrm{V}=$ visual, $\mathrm{VOH}=$ visual or haptic, $\mathrm{VAH}=$ visual and haptic, $\mathrm{H}=$ haptic. $\quad{ }^{*} p<.05 . \quad t p<.01$.
The results comparing the various modality groups on learning appear to be interpretable using the modalityadeptness position proposed by Freides (1974). According to this position, the subject translates each item into the code for the modality that is the most adept for the task to be performed. For the braille task used in this experiment, that is the visual modality (Freides, personal communication, May 25, 1981). Thus, for the visual condition and the two bimodality conditions, this translation would occur only on the test trials, whereas for the haptic condition, it would occur on both study and test trials. Since performance would be inversely related to the frequency with which translation occurs, it would be predicted that performance would be worse in the haptic condition than in the other three conditions, in which the visual modality would be available during study trials, and, that these three groups would perform equivalently. The better performance obtained in the visual condition than in the two bimodality conditions suggests, however, that the availability of the haptic modality during the study trials interfered to some extent with the translation of items into the visual code.

Data from the postexperimental inquiry indicate that some of the subjects in the bimodality conditions may have preferred the presumably less adept haptic modality to the visual modality, suggesting that the modality-adeptness hypothesis does not fully explain the results we obtained. These postexperimental inquiry data suggest also that in subsequent research using bimodality conditions, it would be desirable to observe the extent to which each modality is employed.

\section{REFERENCES}

Freides, D. (1974). Human information processing and sensory modality: Cross-modal functions, information complexity, memory, and deficit. Psychological Bulletin, 81, 284-310.

Hall, A. D., \& Newman, S. E. (1987). Braille learning: Relative importance of seven variables. Applied Cognitive Psychology, 1, 133-141.

Newman, S. E., Hall, A. D., Foster, D. J., \& Gupta, V. G. (1984). Learning as a function of haptic discriminability among items. American Journal of Psychology, 97, 259-272.

Newman, S. E., Hall, A. D., Ramseur, C. J., Foster, D. J., Goldston, D. B., DeCamp, B. L., Granberry-Hager, S. P., Lockhart, J. L., SAwyer, W. L., \& White, J. E., II. (1982). Factors affecting the learning of braille. Journal of Visual Impairment \& Blindness, 76, 59-64.

Newman, S. E., Kindsvater, M. B., \& Hall, A. D. (1985). Braille learning: Effects of symbol size. Bulletin of the Psychonomic Society, 23, 189-190.

(Manuscript received May 19, 1989.) 